\title{
DESAIN BAND PASS FILTER DIGITAL FIR DENGAN METODE KAISER WINDOW UNTUK MEMFILTER SINYAL PINGER 37.5 kHz
}

\author{
Kania Sawitri dan Rustamaji \\ Jurusan Teknik Elektro, Institut Teknologi Nasional \\ Jl. P. H. H. Hasan Mustafa No. 23 Bandung, 40124, Indonesia \\ E-mail: kania.sawitri@yahoo.co.id,rustamajisaja@ymail.com
}

\begin{abstract}
Abstrak
Sinyal pinger dengan frekuensi $37.5 \mathrm{kHz}$ dipancarkan oleh “Beacon black box locator acoustic $37.5 \mathrm{kHz}$ ” yang terdapat pada black box, dapat dideteksi menggunakan sensor berupa hydrophone, yang dilengkapi dengan rangkaian filter yang berfungsi untuk memilah sinyal $37.5 \mathrm{kHz}$ dari sinyal-sinyal lain yang tidak diinginkan. Makalah ini membahas tentang desain band pass filter yang sesuai untuk memilah sinyal pinger yang bekerja pada daerah frekuensi 35.5 sampai dengan $39.5 \mathrm{kHz}$ menggunakan metode Kaiser window. Hasil desain filter yang diperoleh secara respons frekuensi bentuknya sudah sesuai dengan yang direncanakan yaitu respons frekuensi band pass filter digital. Band pass filter digital dengan metode Kaiser window yang dipilih adalah untuk $\beta=3$ dan panjang $N=24$.

Kata kunci: black box, pinger, $37.5 \mathrm{kHz}$, band pass filter, dan Kaiser window
\end{abstract}

\begin{abstract}
A pinger signal with a frequency of $37.5 \mathrm{kHz}$ emitted by "Black box locator beacon acoustic $37.5 \mathrm{kHz}$ " contained in black boxes, can be detected using sensors such as hydrophones, that equipped with a filter circuit that serves to sort out the $37.5 \mathrm{kHz}$ signal from other signals that are not desired. This paper discusses the design of appropriate band pass filter to sort pinger signals that work on the area with the frequencies of 35.5 to $39.5 \mathrm{kHz}$ using the Kaiser window method. The filter design results were obtained in the frequency response shape was according to plan, namely the frequency response of band pass digital filter. The band pass digital filter with Kaiser window method chosen was for $\beta=3$ and the length $N=24$.
\end{abstract}

Keywords: black box, pinger, $37.5 \mathrm{kHz}$, band pass filter, dan Kaiser window

\section{Pendahuluan}

Setiap pesawat terbang terutama pada penerbangan sipil (civil aviation); dilengkapi dengan aviation flight recorders yang lebih dikenal sebagai "black box", yang terdiri dari cockpit voice recorder (CVR) dan flight data recorder (FDR). Untuk mendeteksi keberadaan black box apabila terjadi kecelakaan pesawat terbang di laut, black box dilengkapi dengan underwater locator beacon (ULB) atau underwater acoustic beacon, dikenal sebagai pinger. ULB akan aktif memancarkan (emit) sinyal pinger berupa gelombang ultrasonic "10 ms pulse setiap kali per second pada frekuensi $37.5 \pm 1 \mathrm{kHz}$ ”, apabila tercelup air (water immersion) [1].

Untuk mendeteksi sinyal pinger yang mempunyai frekuensi sebesar $37.5 \mathrm{kHz}$ digunakan hydrophone [2]. Pada hydrophone terdapat rangkaian filter yang berfungsi untuk memilah sinyal $37.5 \mathrm{kHz}$ dari sinyal-sinyal lain yang tidak diinginkan. Dalam penelitian Rustamaji, dkk., untuk memfilter sinyal pinger $37.5 \mathrm{kHz}$ digunakan band pass filter (BPF) digital dengan metode Blackman window diperoleh panjang minimal $\mathrm{N}=10$ [3]. Sedangkan pada penelitian ini, menggunakan metode Kaiser window untuk memperoleh panjang $N$ yang optimal. Desain rangkaian filter ini akan sangat menentukan kemampuan hydrophone dalam pemilahan sinyal pinger, karena itu akan dilakukan perhitungan desain filter yang sesuai untuk memilah sinyal pinger [4][5].

Spesifikasi sinyal pinger yang umum digunakan oleh perangkat ULB dari beberapa pabrikan [4][6][7]:

- Operating Frequency: $37.5 \pm 1 \mathrm{kHz}$.

- Pulse Length: Not less than 9 milliseconds (10 millisecond nominal).

- Pulse Repetition Rate: Not less than 0.9 pulse per second (1 pulse per second nominal).

Sesuai dengan spesifikasi dari sinyal pinger, rangkaian filter yang didesain untuk memilah adalah berupa band pass filter (BPF) digital; direncanakan dapat bekerja pada daerah band frekuensi 35.5 sampai dengan $39.5 \mathrm{kHz}$, dengan frekuensi tengah $37.5 \mathrm{kHz}$. Sehingga BPF dapat memilah sinyal pinger yang mempunyai frekuensi $37.5 \pm$ $1 \mathrm{kHz}$ atau 36.5 sampai dengan $38.5 \mathrm{kHz}$ [8]. 


\section{Metode}

\subsection{Perhitungan BPF Digital dengan Metode Kaiser Window}

BPF digital finite impulse response (FIR) yang didesain menggunakan metode Kaiser window, merupakan bagian dari hydrophone receiver yang berfungsi untuk mendeteksi sinyal pinger seperti pada gambar 1 [3].

Sebelum melakukan realisasi rangkaian BPF digital FIR, dilakukan perhitungan agar diperoleh desain BPF digital FIR sesuai yang diinginkan seperti pada gambar 2 [3].

Desain BPF digital FIR yang akan digunakan untuk menyaring frekuensi sinyal kontinu sinusoida (pinger) $37.5 \pm 1 \mathrm{kHz}$; mempunyai batas frekuensi diantara 35.5 sampai dengan $39.5 \mathrm{kHz}$ atau bandwidth sebesar $4 \mathrm{kHz}$, dengan respons frekuensi seperti pada gambar 3 [3].

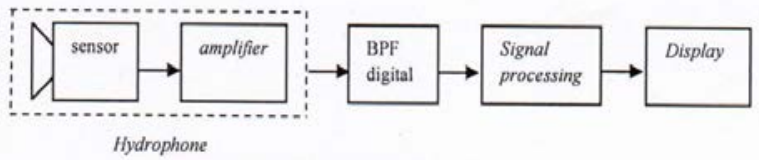

Gambar 1. Diagram blok hydropone receiver

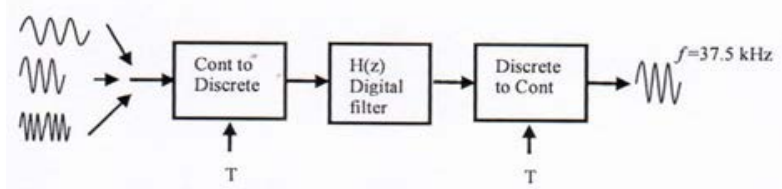

Gambar 2. Diagram blok desain BPF digital

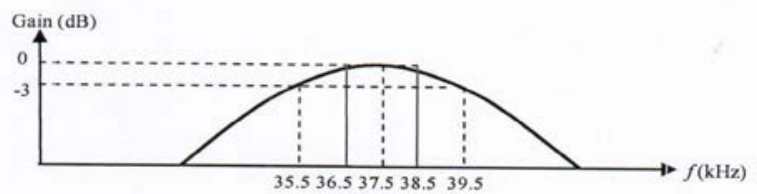

Gambar 3. Respons frekuensi BPF digital finite impulse response (FIR)

\subsection{Aproksimasi Panjang Window $\mathbf{N}$}

Desain BPF digital FIR dengan metode Kaiser window, mempunyai panjang window atau length of window $N$ dihitung berdasarkan aproksimasi Herrmann, dengan parameter filter $N_{s} \delta_{1}, \delta_{2}, \omega_{p}$ dan $\omega_{s}$ [9][10],

$N=\frac{-10 \log _{10}\left(\delta_{1} \delta_{2}\right)-13}{2.324 \Delta \omega}$

dimana pada desain ini dipilih nilai $\delta_{1}=\delta_{2}=\delta=0.1$, dan $\Delta \omega=\omega_{s}-\omega_{p}=2.29336-2.16770=0.12566 \mathrm{rad} / \mathrm{s}$. Sehingga diperoleh aproksimasi nilai $N$ sebesar $23.973 \approx 24$.

Berdasarkan pada hasil aproksimasi, dilakukan desain BPF digital FIR dengan metode Kaiser window untuk $N=24$. Sebagai bahan perbandingan untuk analisis respons frekuensi BPF digital FIR yang didesain, dilakukan perhitungan Kaiser window dengan panjang $N=10$, 15, 20, 24, dan 30 [9][11][12].

\subsection{Perhitungan Respons Frekuensi [3]}

Frekuensi sinyal kontinu (pinger) $f_{0}=37.5 \mathrm{kHz}$ akan difilter dengan menggunakan BPF yang mempunyai frekuensi cut-off $f_{1}=35.5 \mathrm{kHz}$ dan $f_{2}=39.5 \mathrm{kHz}$. Dilakukan konversi frekuensi $(\mathrm{Hz})$ ke frekuensi $(\mathrm{rad} / \mathrm{s})$ dengan persamaan $\quad \Omega=2 \pi f$, diperoleh: $\Omega_{1}=223.053 \mathrm{krad} / \mathrm{s}, \quad \Omega_{2}=248.186 \mathrm{krad} / \mathrm{s}, \quad$ dan $\Omega_{0}=235.620 \mathrm{krad} / \mathrm{s}$. Dipilih sampling rate $f_{s p l}=10^{5}$ sample $/ \mathrm{s}$ atau $T=\frac{1}{f_{s p l}}=10^{-5} \mathrm{~s}$.

Konversi ke bidang diskrit (digital) dilakukan dengan menggunakan persamaan $\omega=\Omega T$, diperoleh: $\omega_{1}=2.23053 \mathrm{rad} / \mathrm{s}, \quad \omega_{2}=2.48186 \mathrm{rad} / \mathrm{s}, \quad \mathrm{dan}$ $\omega_{0}=2.35620 \mathrm{rad} / \mathrm{s}$. Dengan panjang window $N=10,15$, 20, 24, 30 dan menggunakan persamaan

$$
\alpha=\frac{N-1}{2}
$$

diperoleh $\alpha: 4.5,7,9.5,11.5$, dan 14,5 .

Respons frekuensi filter ideal dengan nilai $\alpha$ tertentu :

$H\left(e^{j \omega}\right)=e^{-j \omega \omega}=\left|H\left(e^{j \omega}\right)\right| \angle H\left(e^{j \omega}\right)=1 \angle-\alpha \omega$

mempunyai respons amplitudo filter $\left|H\left(e^{j \omega}\right)\right|$ seperti pada gambar 4.

$\left|H\left(e^{j \omega}\right)\right|=1$, untuk $2.23053 \leq \omega_{c} \leq 2.48186$ dan respons phasa filter $\angle H\left(e^{j \omega}\right)=-\alpha \omega$ rad, menunjukkan respons phasa yang diinginkan linier.

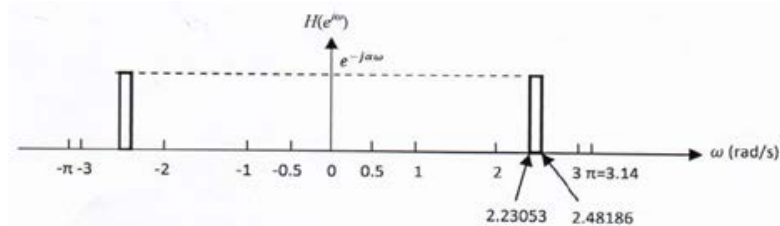

Gambar 4. Respons amplitudo $\| H\left(e^{i-}\right) \mid$ BPF digital ideal yang diinginkan antara $-2 \pi \mathrm{s} / \mathrm{d}+2 \pi$ rad

Mencari respons impuls $h(n)$ bila diketahui $H\left(e^{j \omega}\right)=e^{-j \omega \omega}$ sebagai berikut:

$$
\begin{aligned}
h(n)= & \frac{1}{2 \pi} \int_{0}^{2 \pi} H\left(e^{j \omega}\right) \cdot e^{j \omega n} \\
= & \frac{1}{2 \pi} \int_{-\omega_{2}}^{-\omega_{1}} e^{-j \omega \omega} \cdot e^{j \omega n} d \omega \\
& +\frac{1}{2 \pi} \int_{+\omega_{1}}^{+\omega_{2}} e^{-j \omega \omega} \cdot e^{j \omega n} d \omega \\
= & \frac{\sin \omega_{2}(n-\alpha)}{\pi(n-\alpha)}-\frac{\sin \omega_{1}(n-\alpha)}{\pi(n-\alpha)} \\
= & \frac{\sin 2.48186(n-\alpha)}{\pi(n-\alpha)}-\frac{\sin 2.23053(n-\alpha)}{\pi(n-\alpha)}
\end{aligned}
$$




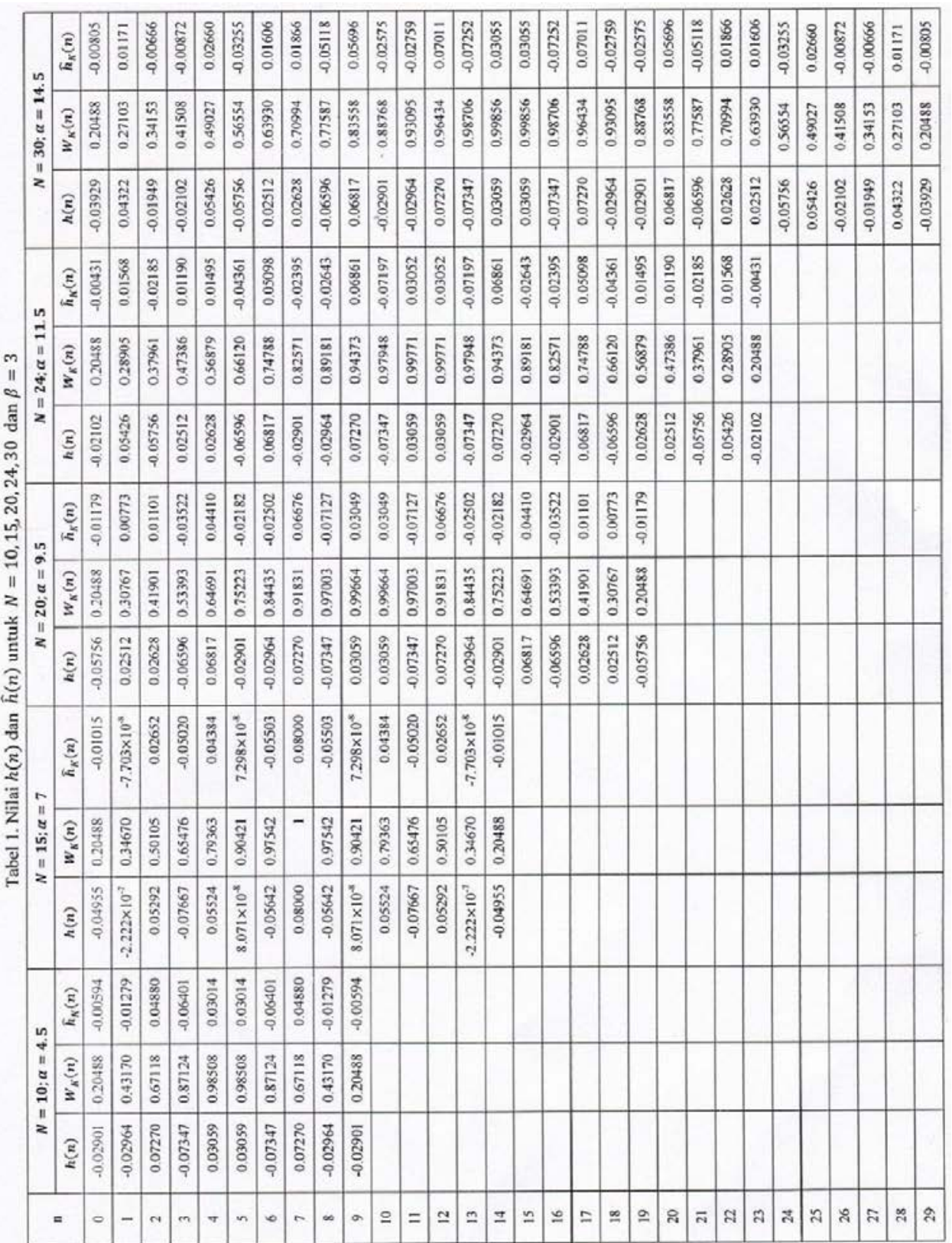

Diperoleh nilai $h(n)$ untuk $N=10,15,20,24$, dan 30 seperti pada tabel 1 . Sehingga respons impuls $h(n)$ :

Untuk $N=24$

$$
\begin{aligned}
h(n)= & -0.02102 \delta(n)+0.05426 \delta(n-1) \\
& -0.05756 \delta(n-2)+0.02512 \delta(n-3) \\
& +0.02628 \delta(n-4)-0.06596 \delta(n-5) \\
& +0.06817 \delta(n-6)-0.02901 \delta(n-7) \\
& -0.02964 \delta(n-8)+0.07270 \delta(n-9) \\
& -0.07347 \delta(n-10)+0.03059 \delta(n-11) \\
& +0.03059 \delta(n-12)-0.07347 \delta(n-13) \\
& +0.07270 \delta(n-14)-0.02964 \delta(n-15) \\
& -0.02901 \delta(n-16)+0.06817 \delta(n-17) \\
& -0.06596 \delta(n-18)+0.02628 \delta(n-19) \\
& +0.02512 \delta(n-20)-0.05756 \delta(n-21) \\
& +0.05426 \delta(n-22)-0.02102 \delta(n-23)
\end{aligned}
$$

\subsection{Kaiser Window}

Persamaan respons impuls Kaiser window $w_{K}(n)$ yang digunakan pada desain filter digital FIR adalah [9][11]:

$w_{k}(n)= \begin{cases}\frac{I_{0}\left[\beta \sqrt{\left(1-\left[\frac{n-\alpha}{\alpha}\right]^{2}\right)}\right]}{I_{0}(\beta)}, & 0 \leq n \leq N-1 \\ 0 & \text { untuk lainnya }\end{cases}$
dimana: $\alpha=\frac{N-1}{2}$.

$I_{0}(x)$ adalah zeroth-order modified Bessel function of the first kind.

$$
I_{0}(\beta) \triangleq \sum_{k=0}^{\infty}\left[\left(\frac{\left(\frac{\beta}{2}\right)^{k}}{k !}\right]^{2}\right.
$$


Parameter Kaiser window: length $N$ dan shape parameter $\beta$; pada desain ini $\beta=3$. Menghitung $\widehat{h}(n)$ bila diketahui window $w_{K}(n)$ :

$\hat{h}(n)=h(n) \cdot w_{k}(n)$

Diperoleh $h(n), w_{F}(n)$ dan $\widehat{h}(n)$ untuk $N=10,15,20$, 24, dan 30 seperti pada tabel 1. Sehingga diperoleh respons impuls $\widehat{h}_{K}(n)$ setelah windowing:

$$
\begin{aligned}
\text { untuk N }= & 24 \\
\hat{h}_{K}(n)= & -0.00431 \delta(n)+0.01568 \delta(n-1) \\
& -0.02185 \delta(n-2)+0.01190 \delta(n-3) \\
& +0.01495 \delta(n-4)-0.04361 \delta(n-5) \\
& +0.05098 \delta(n-6)-0.02395 \delta(n-7) \\
& -0.02643 \delta(n-8)+0.06861 \delta(n-9) \\
& -0.07197 \delta(n-10)+0.03052 \delta(n-11) \\
& +0.03052 \delta(n-12)-0.07197 \delta(n-13) \\
& +0.06861 \delta(n-14)-0.02643 \delta(n-15) \\
& -0.02395 \delta(n-16)+0.05098 \delta(n-17) \\
& -0.04361 \delta(n-18)+0.01495 \delta(n-19) \\
& +0.01190 \delta(n-20)-0.02185 \delta(n-21) \\
& +0.01568 \delta(n-22)-0.00431 \delta(n-23)
\end{aligned}
$$

(9)

\section{Pengujian dan Analisis}

Pengujian yang dilakukan bertujuan untuk mengetahui respons frekuensi dari BPF digital dengan metode Kaiser window yang diperoleh; dengan cara melakukan transformasi fourier pada respons impuls $\widehat{h}_{K}(n)$ sehingga diperoleh respons frekuensi $\hat{H}_{K}\left(e^{j \omega}\right)$. Selanjutnya memberi masukan frekuensi pada $\hat{H}_{K}\left(e^{j \omega}\right)$ dengan rentang $-2 \pi \leq \omega \leq+2 \pi$ radian [9][11].

untuk $N=24$

Dari persamaan (9), dengan transformasi fourier diskrit diperoleh respons frekuensi BPF digital $\widehat{H}_{K}\left(e^{j \omega}\right)$ :

$$
\begin{aligned}
\hat{H}_{K}\left(e^{j \omega}\right)= & -0.00431+0.01568 e^{-j \omega}-0.02185 e^{-j 2 \omega} \\
& +0.01190 e^{-j \partial \omega}+0.01495 e^{-j 4 \omega} \\
& -0.04361 e^{-j 5 \omega}+0.05098 e^{-j 6 \omega} \\
& -0.02395 e^{-j 7 \omega}-0.02643 e^{-j 8 \omega} \\
& +0.06861 e^{-j 9 \omega}-0.07197 e^{-j 10 \omega} \\
& +0.03052 e^{-j 11 \omega}+0.03052 e^{-j 12 \omega} \\
& -0.07197 e^{-j 12 \omega}+0.06861 e^{-j 14 \omega} \\
& -0.02643 e^{-j 15 \omega}-0.02395 e^{-j 16 \omega} \\
& +0.05098 e^{-j 17 \omega}-0.04361 e^{-j 18 \omega} \\
& +0.01495 e^{-j 19 \omega}+0.01190 e^{-j 20 \omega} \\
& -0.02185 e^{-j 21 \omega}+0.01568 e^{-j 22 \omega} \\
& -0.00431 e^{-j 23 \omega} \\
\hat{H}_{K}\left(e^{j \omega}\right)= & e^{-j 11.5 \omega}(0.06105 \cos 0.5 \omega \\
& -0.14393 \cos 1.5 \omega+0.13722 \cos 2.5 \omega \\
& -0.05286 \cos 3.5 \omega-0.04791 \cos 4.5 \omega \\
& +0.10196 \cos 5.5 \omega-0.08723 \cos 6.5 \omega \\
& +0.0299 \cos 7.5 \omega+0.02380 \cos 8.5 \omega
\end{aligned}
$$

$$
\begin{aligned}
- & 0.04370 \cos 9.5 \omega+0.03137 \cos 10.5 \omega \\
- & 0.00861 \cos 11.5 \omega) \\
\left|\hat{H}_{K}\left(e^{j \omega}\right)\right|= & 0.06105 \cos 0.5 \omega-0.14393 \cos 1.5 \omega \\
& +0.13722 \cos 2.5 \omega-0.05286 \cos 3.5 \omega \\
& -0.04791 \cos 4.5 \omega+0.10196 \cos 5.5 \omega \\
& -0.08723 \cos 6.5 \omega+0.0299 \cos 7.5 \omega \\
& +0.02380 \cos 8.5 \omega-0.04370 \cos 9.5 \omega \\
& +0.03137 \cos 10.5 \omega \\
& -0.00861 \cos 11.5 \omega \\
\angle \hat{H}_{K}\left(e^{j \omega}\right)= & -11.5 \omega \mathrm{rad}
\end{aligned}
$$

Besarnya nilai respons frekuensi $\left|\widehat{H}_{K}\left(e^{j \omega}\right)\right|$ untuk nilai $N=10,15,20,24$, dan 30 diperoleh seperti pada tabel 2, dan diplot untuk nilai $\omega=0$ sampai dengan $\omega=\pi \mathrm{rad} / \mathrm{s}$ dengan interval $\pi / 16 \mathrm{rad}$, seperti pada gambar 5 .

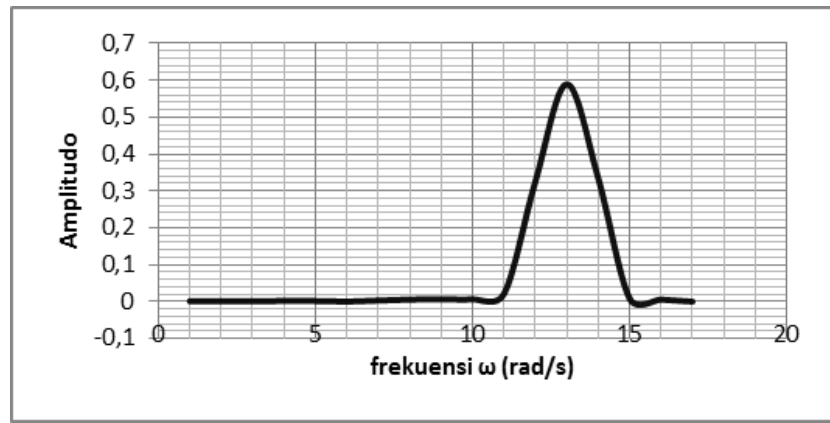

Gambar 5. Respons frekuensi BPF digital dengan $N=24$

Respons frekuensi BPF digital dengan metode Kaiser window yang diperoleh untuk $N=10,15,20,24$, dan 30, mempunyai parameter frekuensi seperti diringkas pada tabel 3.

Secara respons frekuensi, BPF digital yang diperoleh untuk $N=10,15,20,24$, dan 30 bentuknya sesuai dengan yang direncanakan yaitu respons BPF digital. Amplitudo tertinggi untuk $N=24$, yaitu sebesar 0.589655883 .

Untuk $N=10$.

Amplitudo maksimum pada frekuensi sudut $\omega_{0}=$ $2.35619449 \mathrm{rad} / \mathrm{s}$, sebesar 0.245849179 . Nilai $\frac{1}{\sqrt{2}}$ dari amplitudo maksimum adalah 0.1738416216 , terletak pada frekuensi sudut $\omega_{1}=1.9853283997 \mathrm{rad} / \mathrm{s}$ dan $\omega_{2}=$ $2.759079869 \mathrm{rad} / \mathrm{s}$. Terlihat batas bandwidth dari BPF digital hasil windowing melebar dari yang direncanakan, yaitu dari 2.23053 sampai dengan $2.48186 \mathrm{rad} / \mathrm{s}$, menjadi 1.9853283997 sampai dengan $2.759079869 \mathrm{rad} / \mathrm{s}$; atau bandwidth melebar dari sebesar $0.25133 \mathrm{rad} / \mathrm{s}$ menjadi $0.7737514693 \mathrm{rad} / \mathrm{s}$. Melebar $0.052242146 \mathrm{rad} / \mathrm{s}$ atau menjadi 307.862\% dari yang direncanakan. Sehingga mampu memilah sinyal pinger $37.5 \mathrm{kHz}$ atau 2.35620 $\mathrm{rad} / \mathrm{s}$. 
Tabel 2. Nilai $\left\|\vec{H}_{k}\left(e^{\infty}\right)\right\|$ untuk $N=10,15,20,24$, dan 30

\begin{tabular}{|c|c|c|c|c|c|c|c|}
\hline \multirow{2}{*}{ No } & \multirow{2}{*}{$\omega$} & \multicolumn{5}{|c|}{$\left|\boldsymbol{H}_{k}\left(e^{j / 2}\right)\right|$} & \multirow{2}{*}{$\begin{array}{c}N=24 \\
\text { Normalisir }\end{array}$} \\
\hline & & $N=10$ & $N=15$ & $N=20$ & $N=24$ & $N=30$ & \\
\hline 1 & 0 & 0.0076 & 0.010039184 & 0.01006 & 0.001107 & 0.00477 & 0.001877366 \\
\hline 2 & $\pi / 16$ & 0.003752451 & 0.000527482 & 0.004289295 & 0.000482611 & 0.004760671 & 0.000818462 \\
\hline 3 & $2 \pi / 16$ & 0.004227914 & 0.010329763 & 0.006635413 & 0.000732939 & 0.004743333 & 0.001242995 \\
\hline 4 & $3 \pi / 16$ & 0.008571361 & 0.001634702 & 0.010365502 & 0.001743368 & 0.004735805 & 0.002956586 \\
\hline 5 & $4 \pi / 16$ & 0.003958949 & 0.011281683 & 0.00213805 & 0.001643653 & 0.004774869 & 0.002787478 \\
\hline 6 & $5 \pi / 16$ & 0.006904645 & 0.002678409 & 0.009560651 & 3.31022E-05 & 0.004818465 & 5.61382E-05 \\
\hline 7 & $6 \pi / 16$ & 0.01301688 & 0.01364776 & 0.011888221 & 0.002850162 & 0.005003035 & 0.004833602 \\
\hline 8 & $7 \pi / 16$ & 0.000782169 & 0.002834278 & 0.000994075 & 0.005531855 & 0.005445276 & 0.009381498 \\
\hline 9 & $8 \pi / 16$ & 0.037646365 & 0.020399168 & 0.013873435 & 0.006807317 & 0.006413459 & 0.011544559 \\
\hline 10 & $9 \pi / 16$ & 0.098520621 & 0.015180176 & 0.021306866 & 0.006335795 & 0.008606637 & 0.010744902 \\
\hline 11 & $10 \pi / 16$ & 0.166699587 & 0.146353463 & 0.06416369 & 0.020597095 & 0.011115395 & 0.034930705 \\
\hline 12 & $11 \pi / 16$ & 0.221679098 & 0.304666702 & 0.340339662 & 0.32623637 & 0.290351867 & 0.553265692 \\
\hline 13 & $12 \pi / 16$ & 0.245849179 & 0.37208333 & 0.496924307 & 0.589655883 & 0.711740777 & 1 \\
\hline 14 & $13 \pi / 16$ & 0.230548541 & 0.300354383 & 0.32897343 & 0.333966735 & 0.289077541 & 0.566375652 \\
\hline 15 & $14 \pi / 16$ & 0.177472338 & 0.149672309 & 0.075500119 & 0.008231572 & 0.008470716 & 0.013959959 \\
\hline 16 & $15 \pi / 16$ & 0.096123455 & 0.018542239 & 0.020850072 & 0.005572242 & 0.004345275 & 0.00944999 \\
\hline 17 & $16 \pi / 16$ & 0 & 0.030759184 & 0 & 0 & 0 & 0 \\
\hline
\end{tabular}

Tabel 3. Parameter frekuensi BPF digital untuk $N=10,15,20,24$, dan 30 .

\begin{tabular}{ccccccc}
\hline \multirow{2}{*}{ Parameter } & $\begin{array}{c}\text { BPF digital } \\
\text { direncanakan }\end{array}$ & \multicolumn{5}{c}{ BPF digital dengan Kaiser window } \\
\cline { 3 - 7 } & 37.5 & $\mathbf{N}=\mathbf{1 0}$ & $\mathbf{N}=\mathbf{1 5}$ & $\mathbf{N}=\mathbf{2 0}$ & $\mathbf{N}=\mathbf{2 4}$ & $\mathbf{N}=\mathbf{3 0}$ \\
\hline $\mathrm{f}_{0}(\mathrm{kHz})$ & 37.5 & 37.5 & 37.5 & 37.5 & 37.5 \\
$\omega_{0}(\mathrm{rad} / \mathrm{s})$ & 2.3562 & 2.35619449 & 2.35619449 & 2.35619449 & 2.35619449 & 2.35619449 \\
amplitudo & 1 & 0.245849179 & 0.37208333 & 0.496924307 & 0.589655883 & 0.711740777 \\
$\mathrm{f}_{1}(\mathrm{kHz})$ & 35.5 & 31.59748 & 33.46562 & 34.49758 & 35.05264 & 35.49583 \\
$\omega_{1}(\mathrm{rad} / \mathrm{s})$ & 2.23053 & 1.9853284 & 2.102706911 & 2.167547014 & 2.202422226 & 2.2302685 \\
amplitudo & 0.70711 & 0.173841622 & 0.263102646 & 0.351378547 & 0.416949673 & 0.50327673 \\
$\mathrm{f}_{2}(\mathrm{kHz})$ & 39.5 & 43.91212 & 41.4712 & 40.36362 & 39.89337 & 39.49121 \\
$\omega_{2}(\mathrm{rad} / \mathrm{s})$ & 2.48186 & 2.759079869 & 2.605712584 & 2.536121142 & 2.506574136 & 2.48130577 \\
$\mathrm{amplitudo}$ & 0.70711 & 0.173841622 & 0.263102646 & 0.351378547 & 0.416949673 & 0.50327673 \\
$\mathrm{BW}(\mathrm{kHz})$ & 4 & 12.31464 & 8.00558 & 5.866039 & 4.840728 & 3.995382 \\
$\mathrm{BW}(\mathrm{rad} / \mathrm{s})$ & 0.25133 & 0.773751469 & 0.503005673 & 0.368574128 & 0.30415191 & 0.25103727 \\
$\%$ & & $307.86 \%$ & $200.14 \%$ & $146.65 \%$ & $121.02 \%$ & $99.88 \%$ \\
\hline
\end{tabular}

Untuk $N=24$.

Amplitudo maksimum pada frekuensi sudut $\omega_{0}=$ 2.35619449 $\mathrm{rad} / \mathrm{s}$, sebesar 0.589655883. Nilai $\frac{1}{\sqrt{2}}$ dari amplitudo maksimum adalah 0.416949673 , terletak pada frekuensi sudut $\omega_{1}=2.202422226 \mathrm{rad} / \mathrm{s}$ dan $\omega_{2}=$ $2.506574136 \mathrm{rad} / \mathrm{s}$. Terlihat batas bandwidth dari BPF digital hasil windowing sedikit melebar dari yang direncanakan, yaitu dari 2.23053 sampai dengan 2.48186 $\mathrm{rad} / \mathrm{s}$, menjadi 2.202422226 sampai dengan 2.506574136 $\mathrm{rad} / \mathrm{s}$; atau bandwidth melebar dari sebesar 0.25133 $\mathrm{rad} / \mathrm{s}$ menjadi $0.30415191 \mathrm{rad} / \mathrm{s}$. Melebar $0.05282191 \mathrm{rad} / \mathrm{s}$ atau menjadi $121.0170 \%$ dari yang direncanakan. Sehingga mampu memilah sinyal pinger $37.5 \mathrm{kHz}$ atau $2.35620 \mathrm{rad} / \mathrm{s}$.
Untuk $N=30$.

Amplitudo maksimum pada frekuensi sudut $\omega_{0}=$ $2.35619449 \mathrm{rad} / \mathrm{s}$, sebesar 0.71174078 . Nilai $\frac{1}{\sqrt{2}}$ dari amplitudo maksimum adalah 0.50327673 , terletak pada frekuensi sudut $\omega_{1}=2.2302685 \mathrm{rad} / \mathrm{s}$ dan $\omega_{2}=$ $2.48130577 \mathrm{rad} / \mathrm{s}$. Terlihat batas bandwidth dari BPF digital hasil windowing sedikit menyempit dari yang direncanakan, yaitu dari 2.23053 sampai dengan 2.48186 $\mathrm{rad} / \mathrm{s}$, menjadi 2.2302686 sampai dengan 2.48130577 $\mathrm{rad} / \mathrm{s}$; atau bandwidth menyempit dari sebesar 0.25133 $\mathrm{rad} / \mathrm{s}$ menjadi $0.25103727 \mathrm{rad} / \mathrm{s}$. Menyempit 0.00024273 $\mathrm{rad} / \mathrm{s}$ atau menjadi $99.88 \%$ dari yang direncanakan. $\omega_{2}$ yang diperoleh berada di bawah $\omega_{2}$ yang direncanakan. Sehingga BPF digital sudah tidak mampu memilah batas atas sinyal pinger $37.5 \mathrm{kHz}$ (2.35620 rad/s) atau frekuensi $\omega_{2}=2.48186 \mathrm{rad} / \mathrm{s}$. 
Desain BPF digital dengan metode Kaiser window untuk $\beta=3$ dan $N=10,15,20,24,30$ yang direncanakan; dilihat dari respons frekuensinya, yaitu respons BPF semuanya memenuhi persyaratan awal, dan dipilih untuk panjang $N<30$.

Dilihat dari bandwidth yang diperoleh untuk $N=24$ mempunyai bandwidth menjadi $121.0170 \%$ sedikit lebih lebar dari yang direncanakan, lebih mendekati ideal dibandingkan untuk nilai $N$ yang lainnya
Dilihat dari amplitudo normalisasi untuk $N=24$, amplitudo sidelobe tertinggi adalah 0.01154456 atau jauh dibawah $\delta=0.1$ seperti yang dipersyaratkan pada aproksimasi Herrmann; sehingga memenuhi syarat. Jadi BPF digital yang dipilih adalah untuk $N=24$. Dari persamaan (9), diperoleh realisasi rangkaian BPF digital dengan metode Kaiser window $\widehat{h}_{K}(n)$ seperti pada gambar 6 .

Semakin besar nilai $N$ dengan $N<30$, bandwidth BPF digital akan menuju kondisi ideal seperti yang direncanakan; tetapi akan menyebabkan realisasi rangkaian semakin besar dan persamaan untuk algoritma program pada perangkat lunak semakin panjang sehingga tidak efisien.

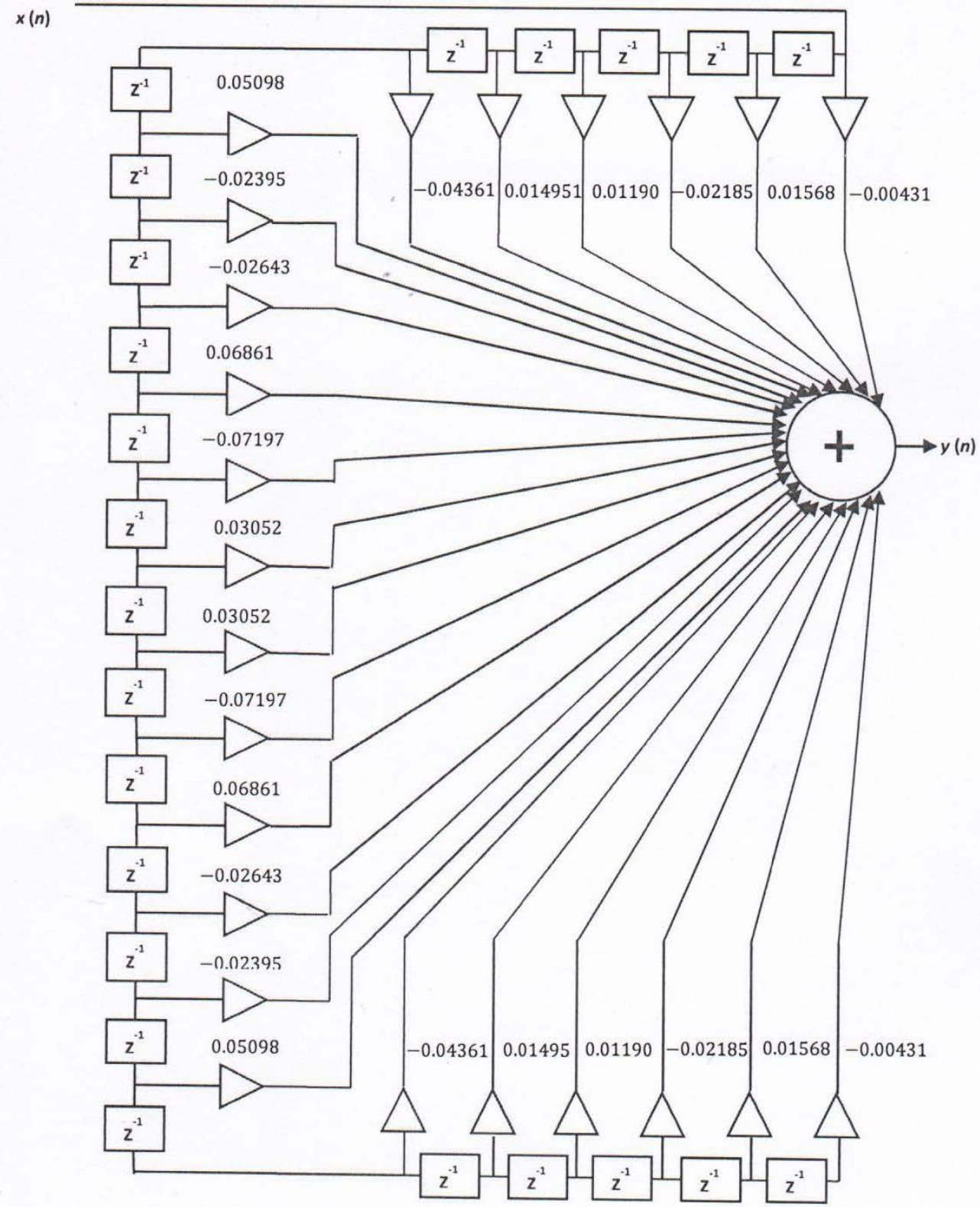

Gambar 6. Realisasi BPF digital untuk $N=24$ 


\section{Kesimpulan}

Berdasarkan hasil desain, pengujian dan analisis disimpulkan bahwa filter digital yang direncanakan dengan metode Kaiser Window untuk nilai $\beta=3$, dan $N$ $=10,15,20,24,30$ secara respons frekuensi bentuknya sudah sesuai dengan yang direncanakan yaitu respons BPF.

Bandwidth dari BPF digital untuk nilai $\beta=3$, dan $N=10$, 15, 20, 24 melebar dari yang direncanakan; sedangkan $N=30$ menyempit dari yang direncanakan. BPF digital untuk $N=24$ mempunyai bandwidth melebar 0.05282191 $\mathrm{rad} / \mathrm{s}$ atau menjadi $121.0170 \%$ dari yang direncanakan dan $\delta=0.01154456$. BPF digital FIR dengan metode Kaiser window untuk $N=24$ yang dipilih.

\section{Referensi}

[1]. Sheng-Shih Wang; Hsien-Sen Hung; Jyh-Jier Ho; Jie-Xian Lin; Chi-Hsiao Yeh. "Improving Detection Technique for Flight Recorders of the Distress Airplanes Crashed into Ocean by Integrating Inertial Navigation System into Underwater Locator Beacon”. Journal of Marine Science and Technology. 2015; Vol. 23, No. 4: pp. 467-474.

[2]. Rafael Barmak; André L. S. C. de Oliveira; Pedro São Thiago; Francisco dos Santos; Marco V. R. Lopes; Geraldo Cernicchiaro. "Underwater locator beacon signal propagation on tropical waters”. Conference: Rio Acoustics 2017”, Rio de Janeiro, Brazil. July 2017.
[3]. Rustamaji; Elan Djaelani. "Desain Band Pass Filter (BPF) Digital dengan Metode Window untuk Memfilter Sinyal Pinger 37.5 kHz yang Dipancarkan dari Beacon Black Box Locator”. Prosiding Seminar Nasional Energi Telekomunikasi dan Otomasi (SNETO) 2015: 28-32.

[4]. ELP-362D Emergency Locator Beacon User's Manual. Teledyne Benthos. 2015.

[5]. "Towed Pinger Locator 25 Specifications". Phoenix International. 2014.

[6]. ATICourses. Applied Technology Institute. Posted by admin in Acoustics \& Sonar, Defense, Including Radar, Missiles and EW on April 8, 2014.

[7]. Rustamaji; Kania Sawitri; Rudi Gunawan; "Perancangan Prototipe Transmitter Beacon Black Box Locator Acoustic 37.5 kHz Pingers”. Jurnal ELKOMIKA | Vol. 4 | No. 2 | Halaman 170 - 184, ISSN (p): 2338-8323 Juli - Desember 2016, ISSN (e): 2459-9638.

[8]. Rustamaji; Pauline Rahmiati; Sarah Permatasari. "Perancangan Prototipe Receiver Beacon Black Box Locator Acoustic $37.5 \mathrm{kHz}$ Pingers”. Jurnal ELKOMIKA Vol. 4 | No. 1 | Halaman 66 - 82, ISSN (p): 2338-8323 Januari - Juni 2016, ISSN (e): 2459-9638.

[9]. Alan V. Oppenheim; Ronald W. Schafer. "Discrete Time Signal Processing”. Prentice-Hall of India, 1996.

[10]. Alan V. Oppenheim; Ronald W. Schafer. "Digital Signal Processing”. Prentice-Hall of India, 1997.

[11]. Lonnie C. Ludeman. "Fundamental of Digital Signal Processing”. John Wiley \& Sons, Inc. 1987.

[12]. Andreas Antonio. "Digital Filter - Analysis, Design and Applications”. McGraw-Hill, 1993. 